fly out with what they wanted and offer little or nothing in return. The community started to view the visitors with amusement, then resentment.

Some people in Shatila, Sukarieh feared, were being 'overresearched' - an anecdotal concern that social scientists and biomedical researchers increasingly encounter at 'high-traffic' research sites around the world. Sometimes, it is a point raised by ethical-review committees. Occasionally, the community under study makes its own frustrations heard loud and clear.

How big is the problem? Ironically, the issue of over-research has not been researched much. In a study published last month, scientists in South Africa analysed concerns about over-research at two sites of HIV-prevention studies (J. Koen, D. Wassenaar and N. Mamotte Soc. Sci. Med. 194, 1-9; 2017).

They found that the term 'over-research' is poorly defined and encompasses a range of concerns. For example, some use it to describe how other communities are being neglected in favour of one with a pre-established research structure or proximity to a university. This can lead to skewed data, and misconceptions about a particular phenomenon or place.

Alternatively, the term could be used to describe a local community that bears the burden of research participation without sufficient reward, creating a sense of frustration that leads to dwindling participation. In biomedical studies, researchers sometimes worry that involvement in multiple clinical trials - and exposure to multiple medications - can increase the risk to participants and cloud results.

Repeated studies can certainly exaggerate the frustration that local people feel when their cooperation produces only data, publications and further research. In the South African study, many locals argued that the research should be more closely linked to developing their communities. Some projects, including certain grants from UNAIDS, a global United Nations effort to tackle HIV/AIDS, do require researchers to invest in infrastructure and education. More funders should look at this model. However, several HIV-prevention studies have done such a good job that their results are inconclusive: too few participants contracted the disease for the data to be statistically meaningful.

It is crucial that efforts to reward research participation are developed in consultation with the community being studied. Sukarieh describes well-intentioned educational courses aimed
"Forging deep links with a community takes time, and time requires funding." at Shatila-research participants that were impractically long - one consisted of 20 hourly sessions - and discussed issues irrelevant to the people's needs.

Over-research can bring benefits, though: a heavily studied community can become savvy in making its needs known to researchers and in influencing how a study is done. In Hackney, an ethnically diverse borough of London that underwent a period of rapid gentrification, a sociologist who came to study participants in a creative-writing group, for example, was told that, to do so, she had to join the group and write pieces like everyone else. The researcher reported how this strengthened her involvement and built stronger links to the community that helped the project to succeed (S. Neal et al. Qual. Res. 16, 491-507; 2016).

Forging deep links with a community takes time, and time requires funding. Funders should recognize the need to build resources for such efforts into their grants; institutions should recognize and reward this time and effort, and acknowledge that it can eat into a researcher's publication record. It is not good enough to come in for a tiny bit, and then leave.

\section{Just the facts}

\author{
Scientists with EPA grants should not be \\ banned from the agency's advisory boards.
}

$\mathrm{S}$ cott Pruitt, administrator of the US Environmental Protection Agency (EPA), levelled a damning accusation against scientists on 31 October. In the interests of restoring scientific "integrity", Pruitt signed a directive stating that the EPA would no longer allow researchers with active grants from the agency to serve on the EPA's scientific advisory boards. By his tally, an unspecified number of scientists in voluntary positions on those boards had received US\$77 million in EPA grants over the past three years - more than enough, Pruitt declared, to raise questions about their ability to provide independent scientific advice.

It was a cynical move - and entirely unnecessary. After all, it is ultimately up to Pruitt and his team to make the appointments to the boards, which advise the agency on everything from basic research programmes to contentious regulatory decisions. If Pruitt wanted to increase the geographical diversity, or include more people from local, state and tribal agencies, as claimed, he could have done so without raising a fuss. Instead, he opted for a public proclamation that singles out active academic scientists as a unique source of bias. He is wrong, on multiple counts.

Scientific enquiry requires money. That's a fact of life. But receiving a research grant is very different from being on the payroll of an institution, advocacy group or company. Those are all very real conflicts of interest that were ignored in Pruitt's directive.

Moreover, winning competitive research grants does not imply fealty to the granting institution. What drives EPA-funded researchers above all is the desire to deliver a public good: discovery and understanding.
Of course, scientific conflicts of interest do exist. So there are established procedures that require scientists to excuse themselves when their own work is under consideration by the boards. These same procedures apply to industry scientists - who are also rightfully represented on the advisory boards - when deliberations involve issues that could affect their companies' bottom lines.

What Pruitt either fails to understand, or has chosen to ignore, is that his advisory boards are designed to focus on science, not policy. Understanding the latest research requires perspectives from the leading scientists. And when it comes to environmental and human-health issues, it is only to be expected that many of those people will have research grants from the EPA.

In the end, Pruitt's directive seems crafted to incite US President Donald Trump's political base, and it's yet another example of researchers being dragged into the political and cultural wars rending the country.

Happily, it is harder to argue with data. This might explain why the first volume of a comprehensive - and congressionally mandated assessment of climate science released on 3 November (see page 152) sailed through reviews from officials at the EPA and other federal agencies.

That report, which integrates the latest climate research, found that greenhouse-gas emissions caused by human activity are altering the planet in fundamental ways. It lays out what we know about the threat of global warming - from deep in the ocean to the highest mountain peaks. And it stands in direct opposition to the climate scepticism voiced by Pruitt and Trump.

Some scientists had feared political interference, but senior officials at federal agencies gave the report the green light, without major changes. This is as it should be: scientists can assess what's known and probe what is not. And it is up to policymakers to decide what to do with that information. This should be a lesson for Pruitt: the current administration has the right to create its own priorities, but it should not and cannot override what science reveals. 